\title{
ARTS EDUCATION AND THE HIGH SCHOOL DROPOUT PROBLEM
}

\author{
M. Kathleen Thomas, Mississippi State University \\ Priyanka Singh, Education Research Center at The University of Texas at Dallas \\ Kristin Klopfenstein, Education Innovation Institute at University of Northern Colorado
}

\begin{abstract}
Arts education advocates believe that quality education in the arts can engage at-risk students in ways other subjects cannot and is therefore an important tool in preventing high school dropout. Although some studies point to lower dropout rates, most do not follow a large number of students over time or account for student and school characteristics expected to influence one's educational path. We fill this gap in the current literature by tracking nearly 175,000 first-time 9th graders for 5 years using survival analysis with longitudinal administrative data from Texas. We find that cumulative credits in the arts are consistently associated with reduced dropout, even after controlling for course completion in core subjects. Our results provide evidence that the arts are a potential lever in education reform. Experimental and/or quasi-experimental research studies are needed to isolate the salient conditions under which arts participation can reduce dropout.
\end{abstract}

\section{WORKING PAPER}

Please do not cite without the permission of the authors.

\begin{abstract}
Author Notes
This research is supported by Spencer Foundation Grant 201200048 awarded to M. Kathleen Thomas. The views expressed are those of the authors and do not necessarily reflect the views of the Spencer Foundation. The conclusions of this research do not necessarily reflect the opinions or official position of the Texas Education Agency, the Texas Higher Education Coordinating Board, or the State of Texas.
\end{abstract}

Correspondence concerning this article should be addressed to M. Kathleen Thomas, Department of Finance and Economics, Mississippi State University, Box 9580, Mississippi State, MS 39762. Email: mkt27@msstate.edu 


\section{INTRODUCTION}

Dropping out of the educational pipeline continues to garner considerable attention at the federal, state, and local level not only because of the sheer numbers of students who are exiting school without a degree and not returning, but because this phenomenon disproportionately affects lowincome, minority, and limited English proficient students. The choice to drop out of high school carries with it substantial personal and societal costs. Dropouts have trouble finding jobs, earn lower wages on average when they do, often experience poor health, and are incarcerated at rates much greater than their more educated peer. Broad solutions to the dropout problem have remained elusive. Despite a huge investment at the federal level totaling more than $\$ 300$ million over the last twenty years, targeted programs and school restructuring seem to have done little to reduce dropout rates (Rumberger, 2011).

Can greater investment in high school arts education be an intervention that works? This is the central thesis of Jessica Hoffman Davis' recent book (2012), Why Our High Schools Need the Arts. Hoffman, founder of the Arts in Education Program at the Harvard Graduate School of Education, proposes that quality education in the arts can engage at-risk students in ways other subjects cannot and is therefore an important tool in fostering student persistence. Courses in the arts involve active learning and are creative and engaging by their very nature. Disciplines such as music and theatre involve practice and performance with peers which can foster student attachment to a group and forge connections between a student and his school. Ask any high school dropout why they didn't finish and you are likely to hear that their classes were boring (Bridgeland, Dilulio, and Morison, 2006). Davis believes that encouraging at-risk students to participate in arts courses is a way to stave this tide of disinterest by enabling these students to 
become agents in their own learning. Students bring their own ideas into the arts classroom and create out of their own life experience.

The arts may also encourage persistence by providing a safe place for students to fail and learn from mistakes in ways that might not be available to them in other subjects. Davis (2012) quotes a theatre teacher explaining how this safety is generated through process oriented learning: "In the arts class, failure is not a bad thing and there is not a strong need for students to be "right." There is a great lesson in the exploration, and results are not framed as such, for it is the process that is the lesson" (p. 73). Process oriented learning is not new, and it is a form of instruction that is not limited to the arts (e.g Volet, 1995). However, Davis maintains the arts support this type of learning well, and that the act of making art causes students to reflect on the progression of their creations and not just the end result. Current research continues to reveal how important it is for students to develop noncognitive skills to be successful (e.g. Heckman, Stixrud, \& Urzua, 2006; Cobb-Clark \& Tan, 2011), particularly perseverance, attention, motivation, and self-confidence (Heckman, 2008). If arts education can produce self-directed, goal-oriented learning in an environment that explicitly supports learning from mistakes, arts students may be able to build the soft skills they need to help them stay in school.

Despite the transformative power that the arts can have in the lives of youth, the flow of resources into arts education is often stagnate at best. According to The Center for Arts Education, New York City public schools eliminated or failed to replace 135 arts teachers during the 2009-10 school year. This left 23 percent of all New York City public schools with no full or part-time licensed instructors in the arts. For the four-year period ending with the 2009-10 school year, the budget for arts supplies, equipment, and musical instruments was also slashed by 80 percent (Israel, 2011). The Los Angeles Unified School District cut the arts education budget by 
76 percent over the last 5 years. As explained by Steven McCarthy, the only remaining member of the district's arts education branch (down from 20 staff members), the realities of school budget cuts are that ..."legal mandates win, and other things fall to the wayside." (Abdollah, October 10, 2012). Mr. McCarthy echoes a common belief in the arts education communitythat the accountability movement largely safeguards traditionally tested subjects such as math and English Language Arts (ELA) from extreme cuts while the arts are often the first to suffer when budgets are constrained. Although eligible for federal funding through the No Child Left Behind Act of 2001 (Sec. 5551 Assistance for Arts Education), arts education is typically not a priority, particularly in schools serving a large fraction of disadvantaged students. Learning in the arts is not assessed on a widespread basis like math and ELA, and consequently, many school districts report reducing instructional time in the arts to allow more time for math and English tutoring (Center on Education Policy, 2006).

A recent Harris Poll surveying 1,000 Americans by telephone reports that 93 percent of respondents agreed that the arts contribute to a well-rounded education and over half rated the importance of arts education as a 10 on a scale of 1-10 (Americans for the Arts, 2005). Although arts advocates and much of the American public believe in the intrinsic value of the arts, the evidence linking arts involvement to student dropout behavior is thin. We have not identified any studies that track a large number of students over time and control for the wide variety of student and school characteristics expected to impact one's educational path. For example, Barry, Taylor, and Walls (1990) conduct a qualitative study by surveying 40 students identified as atrisk. They find that 27 percent of the respondents state they stayed in school because of the arts. The authors supplement the survey with a field study of 11 at-risk students and find that these students are slightly more engaged or "on-task" in their arts classes relative to their non-arts 
classes. Mahoney and Cairns (1997) follow 392 students annually from 7th to 12th grade and find that high school fine arts participation is positively associated with completing 11th grade. Their findings are limited because they track a small number of students from two middle schools, control only for a basic socioeconomic status (SES) index and a teacher rated scale of academic and social competence, and identify extracurricular participation through an examination of school yearbooks.

Catterall (2009) and Catterall, Dumais, and Hampden-Thompson (2012) provide the most rigorous evidence to date that arts participation is associated with reduced dropout and other positive education outcomes by examining nationally representative, longitudinal databases. For example, Catterall (2009) examines about 11,000 students available in all waves of the National Education Longitudinal Study of 1988 (NELS) to see how arts involvement correlates with a variety of education, labor, and civic outcomes. The authors of both studies compare outcomes for low SES/low arts students, low SES/high arts students, high SES/low arts students, and high SES/high arts students. Catterall, Dumais, and Hampden-Thompson (2012) find that more students in the low SES/low arts category (22 percent) fail to graduate high school than those in the low SES/high arts category (4 percent) compared to 7 percent across all SES groups. While both studies benefit from the longitudinal structure of these large databases, the analysis is parsimonious, and the authors do not consider how including other student or school characteristics might weaken the apparent sharp contrasts between arts and non-arts students.

Our main contribution to the current literature is that we track a large number of the same students over time while controlling for a host of student and school characteristics we expect to influence both arts participation and student dropout behavior. The empirical approach we utilize, known as survival or event history analysis, models the amount of time to a particular 
event - in this case dropping out of high school. We follow 174,947 first-time 9th graders who entered a Texas public high school in the fall of 2005 for 5 years using longitudinal administrative data from The University of Texas at Dallas Education Research Center (UTDERC). We advance what we currently know not only because we track a large number of students with varying levels of arts participation until they complete high school or drop out, but because we also control for relevant student and school characteristics. These include the courses students complete in math and ELA - the most frequently tested subjects and the ones most consistently linked to positive education and labor market outcomes. We find that accumulating credits in the arts is consistently associated with reduced dropout and that the estimated hazard ratios for the arts are statistically indistinguishable from the estimated hazard ratios for math and ELA. In other words, the associated effectiveness for completing courses in the arts is on balance with course completion in math and ELA.

\section{DATA}

We estimate the impact of high school arts participation on time to high school dropout by tracking a cohort of students for 5 years using longitudinal state education data from Texas. Identifying dropouts is not an easy task because students often experience periods of time when they are not formally enrolled in school due to family moves or transfers to other schools. Many students do not enter school until after the first official day or are enrolled and are chronically absent. Rumberger (2011) cites long periods of nonenrollment and absenteeism as primary reasons why official dropout rates understate the true dropout problem. It can also be difficult for districts and states to determine if a student has completed high school because students can do so by earning an equivalency certificate or other alternative credential. 
In recent years there has been movement to standardize the process of identifying dropouts to eliminate the wide variation in reported graduation and dropout rates due to different definitions and computational methods. The National Governor's Association issued recommendations to the states to begin using common four-year completion rates and the governors signed a compact in 2005 agreeing to adopt standard definitions (Rumberger, 2011). Specifically, state governors agreed to begin using the four-year adjusted cohort graduation rate which is calculated "by dividing the number of on-time graduates in a given year by the number of first-time entering ninth graders four years earlier" (National Governors Association, 2005). Texas adopted these standard definitions beginning with the 2005-06 academic year. Our observation period begins here because the change in the dropout definition makes prior dropout data incomparable with any year after and including 2005-06 (Texas Education Agency, 2011).

While we define and follow a cohort of students using UTD-ERC data for the survival analysis, we present four-year dropout rates reported in the Academic Excellence Indicator System from the Texas Education Agency here for descriptive purposes. As noted earlier, these rates vary widely by such characteristics as race/ethnicity, limited English proficiency, and atrisk status. Table 1 presents four-year dropout rates for grades 9-12 by various individual characteristics for the Class of 2009, which includes students who began 9th grade for the first time in 2005-06. The new national dropout definition, which Texas adopted in 2005-06, was fully phased in with the Class of 2009 (Texas Education Agency, 2011). Table 1 illustrates how unequal dropout rates are, particularly for disadvantaged students and students of color. Similar to other states and the nation as a whole (Murnane, 2013), low-income, at-risk, special education and students with limited proficiency in English in the state of Texas drop out at higher rates 
than students who do not face such disadvantages. Black, Hispanic, and Native American students in Texas drop out at higher rates than White or Asian students.

The students in our cohort are 9th graders who enter a Texas public high school for the first time in the fall of 2005. We exclude students who attend magnet or charter schools as well as those without 8th-grade Texas Assessment of Knowledge and Skills (TAKS) scores, the standardized assessment used in Texas during our time frame. We also restrict the sample to include only those students who remain at the same high school over our observation period. Details about our censoring procedure follow. Table 2 provides descriptive statistics for the 174,947 first-time 9 th graders in our cohort in the first year of observation-2006. ${ }^{1}$ Covariates include both time-invariant and time-varying characteristics at the student and school level.

We control for the typical individual characteristics expected to influence student persistence that do not vary over time, including race, gender, and measures of prior academic achievement. We also control for typical individual characteristics that can vary over time, including low-income status, at-risk status, and the number of cumulative credits in math, ELA, science, and social studies. The primary variable of interest, the number of cumulative credits in the arts, can also vary over time. The average number of arts credits received for this cohort of 9th graders in 2006 is one half credit. In order to graduate with the recommended or advanced diploma, students in our cohort must complete one Carnegie unit in visual art, music, theatre or dance (Texas Administrative Code, 2010).

Our models also include covariates for school characteristics including total enrollment, racial composition, and the percentage of low-income, special education, or limited English proficient students. All of these school characteristics vary with time. The only school

${ }^{1}$ From this point forward, we refer to the academic year by its spring term. For example, our cohort begins with first time 9th graders in the 2005-06 academic year which we refer to as 2006. 
characteristic in our models that is time-invariant is rural location, which is taken from the 2000 Census.

In the context of survival analysis, dropping out of high school is a failure with a risk profile that can be described over time via a hazard function. Figure 1 depicts the unconditional hazard estimates for time to first dropout for students without a full arts credit, for those who meet the graduation requirement with exactly one credit in the arts, and for those who accumulate more than one credit before they exit high school. The students without a full arts credit include those students with no arts experiences and those students with only minimal exposure - typically the completion of one-half credit. Notice how the hazard function increases with time - the risk of dropping out increases as time passes indicating positive duration dependence. Students facing the lowest risk of dropout in any year, given that they have persisted through the previous year, are the students taking courses in the arts. We see a jump in all of the estimated hazard functions in 2008 when students reach the age at which they can legally leave school. However, without controlling for any other student or school characteristics, we can see in Figure 1 that the risk of dropping out is elevated for students without a full arts credit at every year in our time period.

It is important to note that the estimated hazard functions in Figure 1 depict the difference in time to first dropout for students with and without arts experiences controlling for no other student or school characteristics. Because many of the students who bypass arts education are minority students from economically disadvantaged families (Catterall, 2009), it is likely that at least some of the unconditional difference between the hazard functions is due to other characteristics, both observable and unobservable, that drive student participation in the arts and positive education outcomes. The gap between the estimated hazard functions of those students 
with and without arts experiences could be due to 1) the causal impact that arts participation has on dropping out, 2) selection effects, or 3) the fact that not having met a graduation requirement in the arts is serving as a proxy for not having met other graduation requirements. We use the variables described in Table 2 to control for many of the observable student and school characteristics that influence arts participation and the likelihood of remaining in school. Our conditional analysis is particularly valuable because we control for the other core credits that the students in our cohort are earning over time — credits in math, science, ELA and social studies. This allows us to isolate the marginal impact of completing credits in the arts and eliminate the possibility that any failure to complete credits in the arts is merely serving as a proxy for not completing graduation requirements in the core subjects, a major advancement over what has previously been accomplished by Catterall (2009) and Catterall et al (2012).

\section{ANALYSIS AND RESULTS}

Survival analysis illuminates how the risk of dropping out changes as time passes for the students who have yet to finish or drop out. Standard linear regression techniques are not appropriate in this context because data are right-censored-we do not follow students for a long enough time period to observe all of the ways they ultimately exit high school. From a policy perspective, survival analysis can help identify the riskiest periods for dropout in order for educators to implement appropriate interventions at the most critical times.

Our data are right-censored for the following reasons: 1) students experience the failure event and dropout of high school; 2) students graduate high school; 3) students are still in school at the end of our 5-year observation period; 4) students leave high school for other reasons such as transferring to a private or out-of-state school or choosing to become home-schooled; 5) 
students transfer to another Texas public high school. Once these events occur, the students are no longer at risk of dropping out, therefore, the risk pool is made up of the students who have survived up until that point and are still at risk of dropping out. Table 3 provides the number of dropouts in each year for our cohort of students and how student dropout shrinks the risk pool. Table 3 also records the reduction in the risk pool due to graduation and other censoring events. The number of dropouts steadily increases from year one to year four. In year five, the risk pool shrinks dramatically after most of the students from the initial cohort either graduate or leave the Texas public school system for other reasons.

\section{Cox Proportional Hazards Model with Time Constant Effects: Model 1}

The hazard function given by Equation 1 depicts the risk of dropping out as a function of time for student $i$ in school $j$ in a proportional hazards framework:

$$
h_{i j}(t)=h_{0}(t) \exp \left(\boldsymbol{x}_{i j} \boldsymbol{\beta}_{x}\right)
$$

Equation 1 defines the hazard as a function of the baseline hazard, $h_{0}(t)$, which profiles the risk all students face, modified by the observable student and school characteristics described in Table 2. With the Cox (1972) model, the baseline hazard is not restricted to a particular form, but is assumed to be the same shape for all students (Cleves, Gould, Gutierrez, \& Marchenko, 2010; Singer \& Willett, 2003). Figure 2 reproduces the hazard functions depicted in Figure 1, but now controls for student and school characteristics, assuming time constant coefficients. For comparability, we keep the same scale in both figures. Students who have not earned a full credit in the arts face an increased risk of dropping out of high school at every year in our time frame. However, the gap between those with and without arts experiences is significantly reduced once we control for the observable school and student characteristics defined in Table 2. The students 
in our cohort who face the lowest risk of dropping out are the students who have chosen to study the arts more intensely and have moved beyond the 1-credit graduation requirement.

Model 1 in the first column in Table 4 contains the hazard ratio estimates for this most basic model - the Cox model assuming time constant coefficients. Not surprisingly, as is true in many empirical applications, the proportional hazards assumption does not hold in a model with time constant effects, both globally and for all but a handful of individual covariates, including our variable of interest - total arts credits earned. The Schoenfeld (1982) residuals for almost every covariate are related to time, indicating that the hazard ratios are not constant over time, the primary assumption of the proportional hazards model. Violating this assumption can bias estimates and reduce their precision (Box-Steffensmeier \& Jones, 2004), and we address this shortcoming by estimating a Cox survival model that incorporates time-varying coefficients.

\section{Cox Proportional Hazards Model with Time-Varying Effects and Shared Frailty: Model 2}

Model 2 estimates hazard ratios for each year of our time period. Although there are numerous ways to address nonproportional hazards, allowing regression coefficients to vary over time in an extension of the standard Cox model is one way to deal with the violation of this restrictive assumption (Royston, 2001). Even characteristics that do not change over time, such as race or gender, can potentially have different effects on education outcomes from year to year. For example, there is evidence that the transition from middle school to high school can be challenging for black and Hispanic students, especially for those who experience the narrowing of their peer ethnic groups when moving from 8th to 9 th grade (Benner \& Graham, 2009). Once these students have time to adjust to the high school environment or participate in school 
interventions designed to ease this transition, for example, we might see the impact of race on the risk of dropping out diminish over time.

In addition to allowing the estimated coefficients to vary over time, Model (2) also incorporates a shared frailty term to address selection bias at the school level. Shared frailty survival models are appropriate specifications when one expects observations within a group to be correlated. Accounting for unobserved heterogeneity at the school level is particularly important when examining student dropout because evidence indicates that a majority of our nation's dropouts are produced by a small number of high schools commonly known as "dropout factories" (Balfanz \& Legters, 2004). Even after accounting for observable student and school characteristics, we would expect some students to be at increased risk of dropout because they attend such schools.

Failing to account for unobserved heterogeneity is an omitted variables problem that creates a misspecified model. Essentially, shared frailty can be thought of as a random effects model that accounts for unobservable group effects expected to impact the time to event. An unobserved group frailty effect, $\alpha_{\mathrm{j}}$, enters multiplicatively into the hazard function so that

$$
h_{i j}(t)=h_{0}(t) \alpha_{j} \exp \left(\boldsymbol{x}_{i j} \boldsymbol{\beta}_{x}\right)
$$

The frailty effect is assumed to have mean 1 and variance $\theta$ which is estimated from the data (Cleves, Gould, Gutierrez, \& Marchenko, 2010). Including $\alpha_{j}$ mitigates the selection bias that can arise from unobservable group characteristics affecting student persistence to later grades. Our results show that the shared frailty effect is indeed significant at the 1-percent level indicating the presence of unobserved heterogeneity at the school level. This is consistent with the supposition that some schools create unmeasured risk that increases the chance of student dropout. 
Table 5 provides estimated hazard ratios for four years of our time period for a Cox model that allows the coefficient estimates to vary over time and includes a shared frailty term. The estimates are conditional on $\theta$, the variance of frailty. The proportional hazards assumption holds globally and for most of the individual covariates, including our primary variable of interest, cumulative course credits in the arts. The estimates reported in Table 5 are the exponentiated coefficients. Coefficients greater than 1 indicate the relevant covariate increases the hazard, and the amount greater than 1 indicates the magnitude of the effect in terms of relative risk (Klopfenstein, 2010). A hazard ratio of 1.78 , as can be seen in year two for the atrisk covariate, means the baseline hazard increases by a factor of 1.78 for the at-risk student compared to the student who has not been identified as being at-risk for a given level of frailty. At-risk status is given to a student when he or she meets one or more of several criteria given in the state education code. Some of these criteria include not advancing from one grade to the next, performing poorly on state standardized tests, being pregnant or a parent, and being expelled from school (Texas Education Agency, 2010). For the students who have not yet exited high school, the at-risk student faces a hazard of dropping out that is magnified by 78 percent in year two compared to a similar student who has not been identified as being at-risk. Coefficients less than 1 shrink the baseline hazard. For example, conditional on surviving until year 3, being gifted shrinks the baseline hazard by a factor of 0.48 meaning the probability of dropping out in year three for a gifted student is 48 percent of that of a similar student who does not participate in a gifted program for a given level of frailty.

The results in Table 5 indicate that the effects of most of the student characteristics vary from year to year, indicating Model 2 is a better specification than Model 1. Models with time constant effects hide important information about how race, gender, 8th grade test scores, 
income, at-risk status, gifted program participation, and completed course credits impact the likelihood of dropping out of high school over time. This is particularly apparent for the estimated coefficients for at-risk students. The greatest predictor of dropout is being identified as at-risk, but in the time constant models, the estimates reveal an at-risk student is approximately three times as likely to dropout as a student who is not at risk. When the coefficients are allowed to vary over time, an at-risk student in year one is only 44 percent more likely to dropout than a similar student who has not been identified as at-risk for a given level of frailty. This estimate increases over time, finally ballooning in year four. For the students remaining in the risk pool by year four, who are very different students than those in the risk pool at year one, an at-risk student is 5 times as likely to drop out in year four than a similar student who has not been identified as being at-risk. This may seem surprising given that these students have persisted this long. However, Texas is one of 25 states that by 2010 required high school seniors to pass an exit exam in order to graduate (Rumberger, 2011). Recent research by Helmet and Marcotte (2013), using a difference in differences strategy to estimate causal effects, indicates that the expansion of exit exams across the United States has led to higher dropout rates among 12th graders-even in states that offer alternative pathways to graduation.

As one would expect, successful course completion in all major subjects is associated with reduced risk of dropping out of high school for our cohort of students. Because we control for at-risk status, which should, by definition, identify many of the students who are not progressing toward degree completion, the coefficients on the cumulative course credit variables represent the impact of the specific subjects themselves and not just the fact that a student has received another credit. Furthermore, by controlling for other core subjects, we reduce the likelihood that accumulating credits in the arts is merely serving as a proxy for completing other 
graduation requirements. The hazard ratio estimates for our time-varying course completion variables indicate that receiving credit in an arts course reduces the likelihood of dropping out in all four years. The greatest effect size for course completion in the arts is in the first year when a student earning an additional arts credit faces a hazard that is 59 percent of that of an otherwise similar student for a given level of frailty, indicating that perhaps the best time to encourage students to enroll in arts courses is when they matriculate high school.

The arts appear to be every bit as effective as math and ELA in potentially reducing student dropout. Tests of equality of the coefficients reveal that the estimated coefficients on the arts variables are not significantly different than the math coefficients in years one and four and not significantly different than the ELA coefficients in years one, two, and three. This is important because evidence suggests that schools have been reducing instructional time in the arts in favor of math and ELA (Center on Education Policy, 2006), and students are often pulled out of their arts courses to drill for standardized tests. Based on an author survey of Texas public high schools, 45 percent of the visual art and music teachers who responded reported that their high school had reduced instructional time in the arts to make more time for math and ELA at some point between 2009 and 2011. Sixty-one percent of the respondents reported that students were pulled out of their arts classes in 2012 in the weeks prior to the TAKS to review math, ELA, or science skills. Thirty-one percent reported this occurred very often or often. These results are based on a telephone survey of visual art and music teachers about the characteristics of the arts programs at their Texas public high school during the 2011-12 academic year. We attempted to contact 732 schools, and the results represent a 24 percent response rate. Our results indicate that limiting exposure to arts education for some students in favor of math or ELA tutoring may involve costs not previously considered. 
Given the richness of UTD-ERC data, we posit that at least a portion of the estimated arts effects captures the causal impact of arts participation on reducing high school dropout, especially because we are controlling for many of the observable characteristics that distinguish students who choose to participate in arts education from those who do not. Arts enrollment is a rough approximation of engagement in high school arts education. For many of the students in our cohort, their completion of an arts course is merely compliance with a graduation requirement and not representative of true engagement. But given our current knowledge of the efficacy of arts education, our findings represent a tremendous stride forward and the strongest analysis available to date. Successful completion of courses in the arts is associated with students remaining in school, and our results suggest that the arts might matter as much as math and ELA in reducing dropout. However, to the extent that unobservable student characteristics drive student participation in the arts, we can expect the estimates presented in Table 5 to represent upper bounds on the true impact of arts course completion on high school dropout behavior.

\section{CONCLUSIONS}

To date, the evidence supporting the inclusion of arts education in our public school curriculum has been based largely on correlational studies that fail to account for the student and school characteristics that drive both arts participation and high school dropout. We have pushed the field forward by utilizing longitudinal education data from the state of Texas and employing a more rigorous methodology to explore the link between earning arts credits, accumulated over time, and dropout behavior. By using survival analysis, we have shown how the risk of dropping out changes over time for the students who have yet to complete high school or drop out and that the best time to encourage arts participation is early in a student's high school career. We have 
also shown that the gap between the estimated hazard rates for students with and without arts experiences closes substantially once we include school and student covariates in the models, but it does not disappear. This is particularly telling given recent evidence that some positive education outcomes might be driven entirely by the observable characteristics of students who choose to enroll in courses in the arts. ${ }^{2}$ We do not find that to be the case here.

Because arts environments are not randomly assigned across high schools, we account for school level selection by incorporating shared frailty in a model with time-varying coefficients. We also control for the number of credits students complete over time in math, ELA, science, and social studies to ensure that accumulating credits in the arts is not merely serving as a proxy for accumulating credits in the other core subjects required for graduation. Estimates from our survival analysis show that the arts are every bit as effective at reducing student dropout as math and ELA. However, because we are unable to account for unobserved individual heterogeneity, we cannot ignore the possibility that our results could be partially driven by student-level selection into the arts. Courses in the visual arts, music, theatre, and dance are not required subjects for all Texas students to graduate in our years of observation, and only one credit in one artistic discipline is required for those students who are college-bound. We cannot know the counterfactual outcome - if the students who chose to accumulate multiple credits in the arts would have graduated anyway, even if they had not participated in arts courses while in high school.

Because we lack a clear identification strategy, we fall short of making the causal claim that would justify recommending investment in arts education as a specific strategy schools undertake to address the high school dropout problem. However, we do believe our results

\footnotetext{
${ }^{2}$ See Elpus (2013) for evidence that the SAT and math standardized test scores of music versus non-music students are no different when controlling for demographic and prior achievement variables contained in the ELS.
} 
suggest that when faced with budget cuts, the automatic response should not be to cut the arts from our public schools, especially for those schools with high dropout rates. Given the current state of the economy and the proliferation of budget cuts to arts education that have already occurred, this is a challenging proposition. A recent report from the U.S. Department of Education (Parsad \& Spiegelman, 2011) reveals that over the last decade (2000-10), the percentage of public elementary schools and high schools offering courses in the visual arts, theatre, and dance all declined, despite increased public school enrollment over the same period (Aud et al, 2012).

The next step for the field should be the undertaking of experimental and/or quasiexperimental research studies that can isolate the most promising conditions under which arts participation can mitigate the high school dropout problem. This potential certainly exists. For example, while historically the National Endowment for the Arts (NEA) has not provided competitive grant funding for researchers, it began an initiative in 2012 to fund small one-year research studies to examine the impact of the arts using existing data from a variety of sources. In 2013, the NEA awarded a total of $\$ 350,000$ to 17 organizations through its Art Works Research Grant Program. This is a move in the right direction and a significant achievement for the NEA given increased political pressure to reduce federal spending. But we surmise that the field has exhausted the benefits of small-scale research studies that produce localized and largely descriptive evidence of the impact of the arts. We suggest that the NEA and other interested stakeholders pool resources and seek to fund one or two large-scale, multi-year studies that propose to use an experimental or quasi-experimental research design. Our results using administrative data indicate that investing in such efforts could be fruitful for the field. 


\section{References}

Abdollah, T. (October 10, 2012). LAUSD arts funding cut 76 percent in five years. 89.3 KPCC Southern California Public Radio. Retrieved 11/28/12 from http://www.scpr.org/blogs/education/2012/10/10/10421/lausd-arts-funding-cut76-five-years/.

Americans for the Arts. (2005). New Harris Poll reveals that 93 percent of Americans believe that the arts are vital to providing a well-rounded education. Retrieved 10/12/12 fromhttp://www.americansforthearts.org/news/press/2005/ 2005_06_13b.asp.

Aud, S., Hussar, W., Johnson, F., Kena, G., Roth, E., Manning, E., Wang, X., and Zhang, J. (2012). The Condition of Education. 2012 NCES 2012-045. U.S. Department of Education, National Center for Education Statistics. Washington, DC. Retrieved 11/29/12 from http://nces.ed.gov/pubsearch.

Balfanz, R. \& Legters, N. (2004). Locating the dropout crisis: Which high schools produce the nation's dropouts? Where are they located? Who attends them? Report 70. Center for Research on the Education of Students Placed At Risk. Retrieved 06/12/13 from http://www.csos.jhu.edu/crespar/techReports/ Report70.pdf.

Barry, N, Taylor. J. \& Walls, K.(1990). The role of the fine and performing arts in high school dropout prevention. Center for Music Research, Florida State University. Retrieved 06/12/13 from http://www.eric.ed.gov/ PDFS/ED354168.pdf. 
Benner, A.D. \& Graham, S. (2009). The transition to high school as a developmental process among multiethnic urban youth. Child Development, 80, 356-376.

Box-Steffensmeir, J. M. \& Jones, B. S. (2004). Event history modeling: A guide for social scientists. New York: Cambridge University Press.

Bridgeland, J. M., DiIulio, Jr., J. J. \& Morison, K. B. (2006). The Silent Epidemic:

Perspectives of High School Dropouts. A report by Civic Enterprises in association with Peter D. Hart Research Associates for the Bill and Melinda Gates Foundation. http://www.gatesfoundation.org/united-states/Documents/ TheSilentEpidemic3-06Final.pdf.

Catterall, J.S. (2009). Doing Well and Doing Good by Doing Art: A 12-Year National Study of Education in the Visual and Performing Arts; Effects on the Achievements and Values of Young Adults. Los Angeles: Imagination Group.

Catterall, J.S., Dumais, S. A., \& Hampden-Thompson, G. (2012). The arts and achievement in at-risk youth: Findings from four longitudinal studies. Research Report \#55. Washington, DC: National Endowment for the Arts.

Center on Education Policy. 2006. From the Capital to the Classroom: Year Four of the No Child Left Behind Act. Washington, DC.

Cleves, M., Gould, W., Gutierrez, R. \& Marchenko, Y. (2010). An introduction to survival analysis using Stata. 3rd edition. College Station, TX: Stata Press.

Cobb-Clark, D. A. \& Tan, M. (2011). Noncognitive skills, occupational attainment, and relative wages. Labour Economics, 18, 1-13.

Cox, D.R. (1972). Regression models and life-tables (with discussion). Journal of the Royal Statistical Society, Series B, 187-220. 
Davis, J. H. (2012). Why our high schools need the arts. New York: Teachers College Press.

Elpus, K. (2013). Is it the music or is it selection-bias? A nationwide analysis of music and non-music students' SAT scores. Journal of Research in Music Education, 61, 175-194.

Heckman, J.J. (2008). Schools, skills, and synapses. Economic Inquiry, 46, 289-324.

Heckman, J.J., Stixrud, J., \& Urzua, S. (2006). The effects of cognitive and noncognitive abilities on labor market outcomes and social behavior. Journal of Labor Economics, 24, 411-482.

Hemelt, S.W. \& Marcotte, D.E. (2013). High school exit exams and dropout in an era of increased accountability. Journal of Policy Analysis and Management, 32, 323350.

Israel, D. 2011, July. Accelerating arts education funding cuts and loss of arts teachers paint grim picture for city schools. The Center for Arts Education. Retrieved 11/27/12 from www.cae-nyc.org/sites/default/files/docs/Research-BriefAccelerating-Arts-Education-Cuts-June-2011.pdf.

Klopfenstein, K. (2010). Does the Advance Placement program save taxpayers money? The effect of AP participation on time to college graduation. In P.M. Sadler, G. Sonnert, R. H. Tai, and K. Klopfenstein (Editors), AP: A Critical Examination of the Advanced Placement Program. Cambridge, MA: Harvard Education Press.

Mahoney, J. L. \& Cairns, R. B. (1997). Do extracurricular activities protect against early school dropout? Developmental Psychology, 33, 241-53. 
Murnane, R. J. (2013). U.S. high school graduation rates: Patterns and explanations. Journal of Economic Literature, 51, 370-422.

National Governors Association (2005). Graduation Counts: A Compact on State High School Graduation Data. Retrieved 08/07/13 from http://www.nga.org/files/live/sites/NGA/files/pdf/0507GRADCOMPACT.PDF.

No Child Left Behind Act of 2001, 20 U.S.C., 6301 et. seq. (2009).

Parsad, B., \& Spiegelman, M. (2011). A Snapshot of Arts Education in Public Elementary and Secondary Schools: 2009-10 (NCES 2011-078). National Center for Education Statistics, Institute of Education Sciences, U.S. Department of Education. Washington, DC.

Royston, P.R. (2001). Flexible parametric alternatives to the Cox model, and more. The Stata Journal. 1, 1-28.

Rumberger, R. W. (2011). Dropping out: Why students drop out of high school and what can be done about it. Cambridge, MA: Harvard University Press.

Rumberger, R. W.\& Larson, K. A. (1998). Student mobility and the increased risk of high school dropout. American Journal of Education, 107, 1-35.

Rumberger, R. W. \& Palardy, G. J. (2005). Test scores, dropout rates, and transfer rates as alternative indicators of high school performance. American Educational Research Journal. 42, 3-42.

Schoenfeld, D. (1982). Partial residuals for the proportional hazards regression model. Biometrika 69, 239-41.

Singer, J. D. \& Willett, J. B. (2003). Applied longitudinal data analysis: Modeling change and event occurrence. New York: Oxford University Press. 
Texas Administrative Code. (2010). Title 19, Part 2, Chapter 74, Subchapter E, Rule $\S 74.54$.

Texas Education Agency. (2011). Secondary school completion and dropouts in Texas public schools, 2009-10 (Document No. GE11 601 08). Austin, TX: Author.

-----(2010). Academic Excellence Indicator System Glossary. Retrieved on 08/07/13 from http://ritter.tea.state.tx.us/perfreport/aeis/2010/glossary.html.

Texas Legislature. (2009). H.B. 3. Retrieved 08/09/13 from http://www.legis.state.tx.us/billlookup/text.aspx?LegSess=783\&Bill=HB3. Volet, S. (1995). Process-oriented instruction: A discussion. European Journal of Psychology of Education: 10, 449-59. 
Table 1: Four-Year dropout rates (percent)by race/ethnicity and disadvantaged status for 9-12th grade students in Texas public schools: Class of 2009

\begin{tabular}{ll}
\hline \hline & Dropout Rates (Percent) \\
Overall 4-Year (Grades 9-12) & 9.4 \\
Race/Ethnicity & 14.8 \\
Black & 12.4 \\
Hispanic & 4.5 \\
White & 3.0 \\
Asian & 9.3 \\
Native American & \\
Disadvantaged Status & 10.9 \\
Economically Disadvantaged & 12.4 \\
At-Risk & 29.1 \\
Limited English Proficient & 14.1 \\
Special Education & \\
\hline \hline Source: Texas Edcation Agency, Academic Excellen
\end{tabular}

Source: Texas Education Agency, Academic Excellence Indicator System

Dropout rates for the Class of 2009 are from the 2009-2010 State Performance Report found at http://ritter.tea.state.tx.us/perfreport/aeis/2010/state.html. 
Table 2: Descriptive statistics for first-time 9th graders in Texas public high schools in 2006

Mean Std Dev Min Max Description

Time-Constant Student Characteristics

\begin{tabular}{|c|c|c|c|c|c|}
\hline Male & 0.49 & 0.50 & 0 & 1 & Male \\
\hline Black & 0.11 & 0.32 & 0 & 1 & Black \\
\hline Hispanic & 0.39 & 0.49 & 0 & 1 & Hispanic \\
\hline Asian & 0.03 & 0.18 & 0 & 1 & Asian \\
\hline Native American & 0.00 & 0.06 & 0 & 1 & Native American \\
\hline 8th Grade Math TAKS (Z-Score) & 0.10 & 0.97 & -3.22 & 1.78 & Standardized test score in math transformed to a z-score \\
\hline 8th Grade Reading TAKS (Z-Score) & 0.09 & 0.93 & -5.08 & 0.99 & Standardized test score in reading transformed to a $\mathrm{z}$-score \\
\hline \multicolumn{6}{|l|}{ Time-Constant School Characteristics } \\
\hline Rural (2000 Census) & 0.31 & 0.46 & 0 & 1 & High school located in rural area \\
\hline \multicolumn{6}{|l|}{ Time-Varying Student Characteristics } \\
\hline Low-Income & 0.42 & 0.49 & 0 & 1 & Identified as economically disadvantaged \\
\hline At-Risk & 0.42 & 0.49 & 0 & 1 & Identified as at-risk of dropping out \\
\hline Gifted & 0.12 & 0.33 & 0 & 1 & Identified as gifted \\
\hline Limited English Proficient & 0.04 & 0.19 & 0 & 1 & Identified as limited English proficient \\
\hline Special Ed & 0.03 & 0.17 & 0 & 1 & Identified as Special Ed Students \\
\hline
\end{tabular}




\begin{tabular}{|c|c|c|c|c|c|}
\hline Cumulative Science Credits & 0.85 & 0.34 & 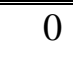 & 3 & Total science credits earned in year1 \\
\hline Cumulative Math Credits & 0.82 & 0.38 & 0 & 3 & Total math credits earned in year 1 \\
\hline Cumulative English Lang Arts Credits & 1.25 & 0.64 & 0 & 5.5 & Total English language arts credits earned in year 1 \\
\hline Cumulative Social Science Credits & 0.87 & 0.33 & 0 & 5 & Total social science credits earned in year 1 \\
\hline Cumulative Arts Credits & 0.53 & 0.64 & 0 & 4 & Total arts credits earned in year 1 \\
\hline \multicolumn{6}{|l|}{ Time-Varying School Characteristics } \\
\hline Percent Low-Income & 41.21 & 23.85 & 0 & 100 & Percent identified as economically disadvantaged \\
\hline Percent Limited English Proficient & 6.08 & 6.69 & 0 & 38.2 & Percent identified as limited English proficient \\
\hline Percent Black & 12.64 & 14.91 & 0 & 91.4 & Percent Black \\
\hline Percent Hispanic & 38.65 & 29.62 & 0 & 100 & Percent Hispanic \\
\hline Total Enrollment & 1,915 & 1,027 & 52 & 4,872 & Number of students \\
\hline Total Enrollment Squared & 4,724 & 4,434 & 2.7 & 23,736 & Number of students squared (in thousands) \\
\hline
\end{tabular}

Source: UTD-ERC data; $\mathrm{N}=174,947$; Descriptive statistics for time-varying variables are for the initial year of study. The sample excludes students attending

charters, magnets, and campuses that include grades other than the 9-12 grade span. 
Table 3: Number of Texas public high school dropouts (2006-2010)

\begin{tabular}{|c|c|c|c|c|c|c|}
\hline \multirow[t]{4}{*}{ 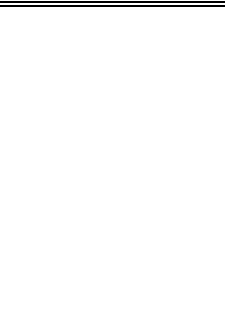 } & \multirow[t]{4}{*}{ Total } & \multirow{4}{*}{$\begin{array}{l}\text { Number } \\
\text { Persisting }\end{array}$} & Number & \multirow{3}{*}{$\begin{array}{l}\text { Censored } \\
\text { at } \\
\text { Graduation }\end{array}$} & \multirow{2}{*}{$\begin{array}{l}\text { Censored } \\
\text { When }\end{array}$} & \multirow{3}{*}{$\begin{array}{l}\text { Censored } \\
\text { When Leaving } \\
\text { for Other }\end{array}$} \\
\hline & & & Dropping & & & \\
\hline & & & Out & & Changing & \\
\hline & & & & & Schools & Reasons \\
\hline (9th) Year 1 & 174,947 & 156,410 & 567 & 0 & 14,107 & 3,863 \\
\hline (10th) Year 2 & 154,100 & 141,948 & 1,115 & 7 & 7,131 & 3,899 \\
\hline (11th) Year 3 & 139,750 & 128,974 & 1,356 & 2,540 & 3,540 & 3,340 \\
\hline (12th) Year 4 & 126,377 & 5,571 & 1,701 & 116,679 & 150 & 2,276 \\
\hline Year 5 & 3,904 & 820 & 962 & 1,745 & 0 & 377 \\
\hline
\end{tabular}

Source: UTD-ERC

Notes: We begin with 268,625 9th graders in 2006 and exclude 31,392 repeaters in order to include only first-time ninth graders. We eliminate 45,813 students without a valid 8th grade TAKS math or English score in 2005 and 16,473 students who moved to a magnet or charter school during our time frame. This leaves us with a cohort of 174,947 students in Year 1. 
Table 4: Time constant hazard ratio estimates for subset of covariates: Model (1)

\begin{tabular}{|c|c|c|}
\hline & & Cox \\
\hline Time-Constant Variables & & (1) \\
\hline \multirow[t]{10}{*}{ Student Characteristics } & Male & $0.79 * * *$ \\
\hline & & $(0.03)$ \\
\hline & Black & $0.86^{*}$ \\
\hline & & $(0.06)$ \\
\hline & Hispanic & $0.89 *$ \\
\hline & & $(0.05)$ \\
\hline & Math TAKS (Z-Score) & $0.70 * * *$ \\
\hline & & $(0.02)$ \\
\hline & Reading TAKS (Z-Score) & $0.92 * * *$ \\
\hline & & $(0.01)$ \\
\hline
\end{tabular}

Time-Varying Variables

Student Characteristics

Low-Income

$1.10^{*}$

(0.05)

At-Risk

$3.03 * * *$

(0.24)

Gifted

$0.61 * * *$

(0.06)

Special Ed

$0.46^{* * *}$

(0.04)

Cum Math Credits

$0.74 * * *$

(0.02) 


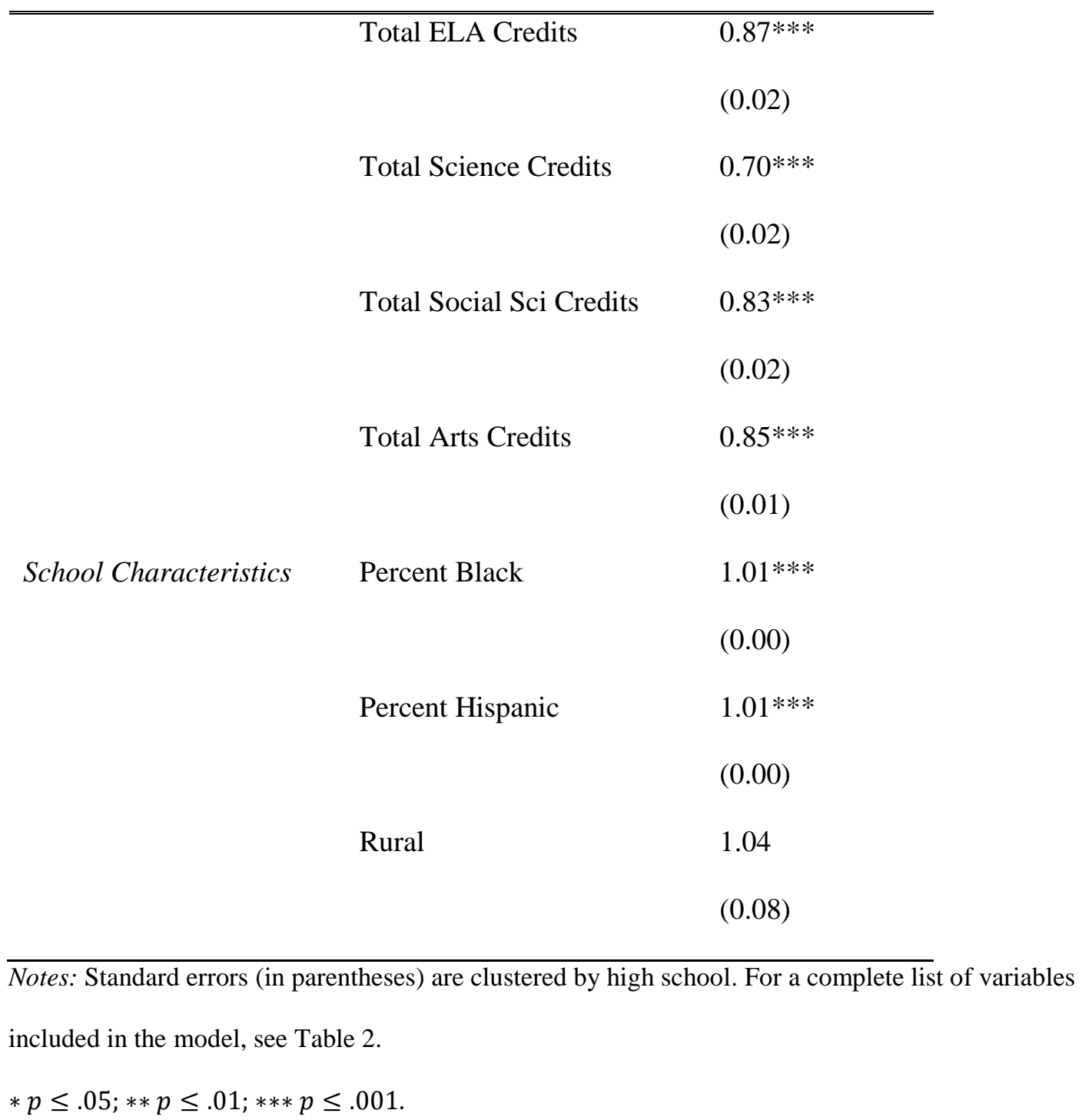


Table 5: Time varying hazard ratio estimates for subset of covariates for Cox proportional hazard with shared frailty: Model (2)

\begin{tabular}{|c|c|c|c|c|}
\hline & Year 1 & Year 2 & Year 3 & Year 4 \\
\hline \multicolumn{5}{|l|}{ Student Characteristics } \\
\hline \multirow[t]{2}{*}{ Male } & $0.67 * * *$ & $0.77 * * *$ & $0.73 * * *$ & $0.71 * * *$ \\
\hline & $(0.06)$ & $(0.05)$ & $(0.04)$ & $(0.04)$ \\
\hline \multirow[t]{2}{*}{ Black } & $0.54 * * *$ & $0.69 * *$ & $0.77 *$ & 1.16 \\
\hline & $(0.10)$ & $(0.09)$ & $(0.09)$ & $(0.11)$ \\
\hline \multirow[t]{2}{*}{ Hispanic } & 0.91 & $0.81 *$ & $0.76^{* *}$ & 0.96 \\
\hline & $(0.12)$ & $(0.08)$ & $(0.07)$ & $(0.08)$ \\
\hline \multirow[t]{2}{*}{ Math TAKS (Z-Score) } & $0.84 * *$ & $0.90 *$ & $0.91 *$ & $0.62 * * *$ \\
\hline & $(0.06)$ & $(0.04)$ & $(0.04)$ & $(0.02)$ \\
\hline \multirow[t]{2}{*}{ Reading TAKS (Z-Score) } & 0.95 & 1.01 & 1.00 & $0.88 * * *$ \\
\hline & $(0.04)$ & $(0.03)$ & $(0.03)$ & $(0.02)$ \\
\hline \multirow[t]{2}{*}{ At-Risk } & $1.44 * *$ & $1.78 * * *$ & $2.74 * * *$ & $5.24 * * *$ \\
\hline & $(0.19)$ & $(0.21)$ & $(0.33)$ & $(0.54)$ \\
\hline \multirow[t]{2}{*}{ Gifted } & 0.56 & 0.85 & $0.48 * *$ & 0.71 \\
\hline & $(0.18)$ & $(0.18)$ & $(0.12)$ & $(0.13)$ \\
\hline \multirow[t]{2}{*}{ Special Ed } & 0.57 & 0.87 & 0.80 & $0.27 * * *$ \\
\hline & $(0.18)$ & $(0.13)$ & $(0.10)$ & $(0.04)$ \\
\hline \multirow[t]{2}{*}{ Cum Math Credits } & $0.47 * * *$ & $0.56 * * *$ & $0.62 * * *$ & $0.82 * *$ \\
\hline & $(0.07)$ & $(0.04)$ & $(0.03)$ & $(0.03)$ \\
\hline Cum ELA Credits & $0.42 * * *$ & $0.72 * * *$ & $0.80 * * *$ & $0.91 * *$ \\
\hline
\end{tabular}




$$
(0.04) \quad(0.03) \quad(0.02) \quad(0.02)
$$

$\begin{array}{lllll}\text { Cum Science Credits } & 0.41 * * * & 0.52 * * * & 0.62 * * * & 0.97\end{array}$

$$
(0.06) \quad(0.04) \quad(0.03) \quad(0.04)
$$

Cum Social Sci Credits $\quad 0.32 * * * \quad 0.48 * * * \quad 0.64 * * * \quad 0.67 * * *$

$$
(0.05) \quad(0.03) \quad(0.03) \quad(0.02)
$$

$\begin{array}{lllll}\text { Cum Art Credits } \quad 0.59 * * * & 0.78 * * * & 0.84 * * * & 0.84 * * *\end{array}$

$$
(0.07) \quad(0.04) \quad(0.03) \quad(0.02)
$$

School Characteristics

$\begin{array}{lrrrr}\text { Percent Black } & 1.02 * * & 1.02 * * * & 1.01 * * & 1.00 \\ & (0.00) & (0.00) & (0.00) & (0.00) \\ \text { Percent Hispanic } & 1.01 & 1.01 * * * & 1.01 * * * & 1.00 \\ & (0.00) & (0.00) & (0.00) & (0.00) \\ \text { Rural } & 1.38 * & 1.53 * * * & 1.42 * * & 0.84 \\ & (0.21) & (0.18) & (0.15) & (0.09)\end{array}$

Theta, variance of frailty $\quad 0.28$

Notes: Standard errors in parentheses. Shared frailty based on high school attended. For a complete list of variables included in the model, see Table 2.

$* p \leq .05 ; * * p \leq .01 ; * * * p \leq .001$. 
Figure 1: Unconditional smoothed hazard rate estimates for time to first dropout by arts credits

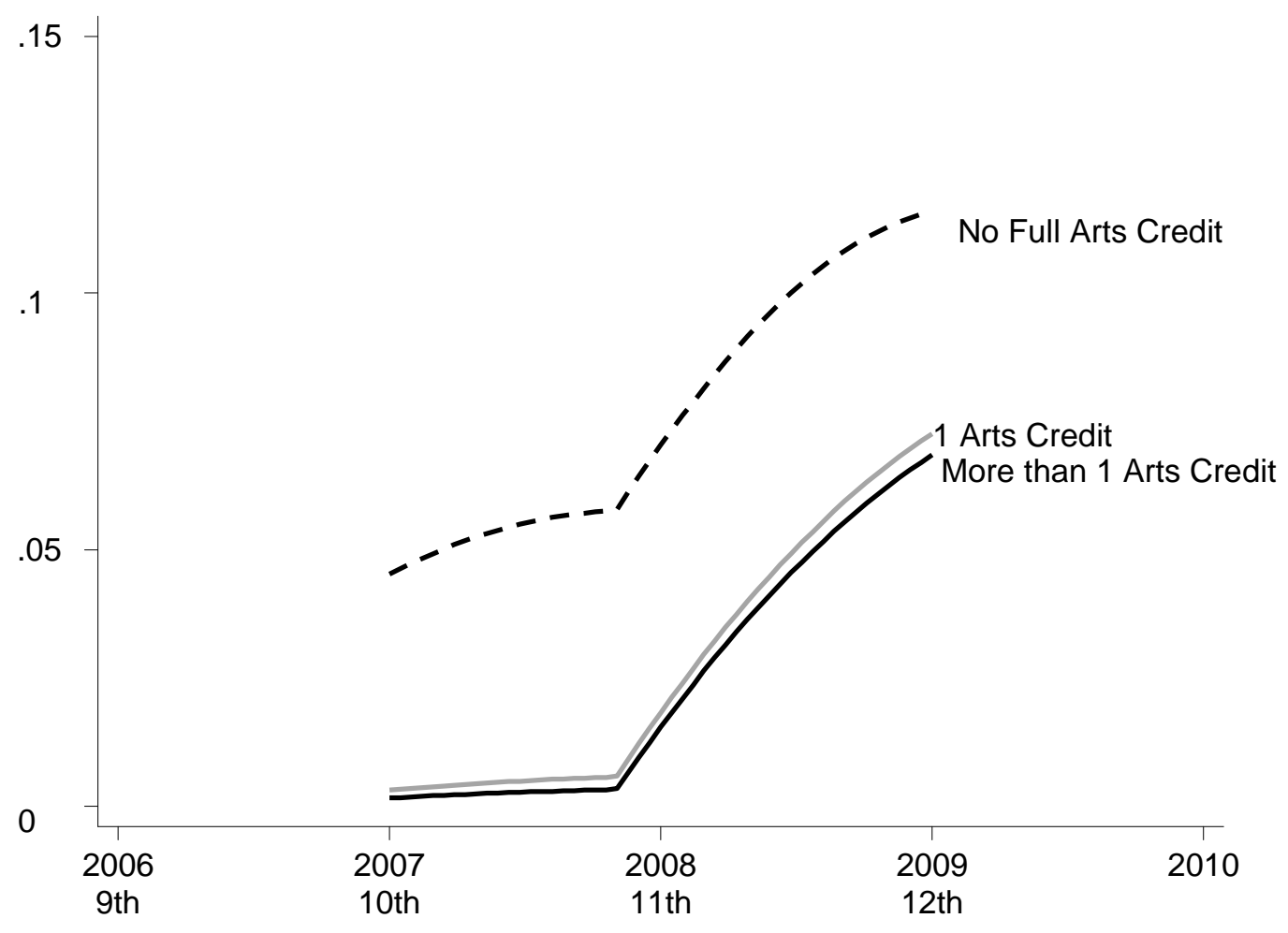

Source: UTD-ERC

Notes: Figure 1 depicts the typical on-time progression to graduation. Every year after 2006 includes the students repeating previous grades. We estimate hazards by smoothing the Nelson-Aalen cumulative hazard with a kernel (Gaussian) smoother. Although we follow our cohort for 5 years, beginning and ending years in our time period are not plotted because of the boundary bias kernel smoothing creates due to insufficient data at the endpoints. The null hypothesis for the equality of the hazard functions can be rejected at greater than the 99 percent confidence level using log rank test statistics. 
Figure 2: Conditional smoothed hazard rate estimates for time to first dropout by arts credits (time constant coefficients)

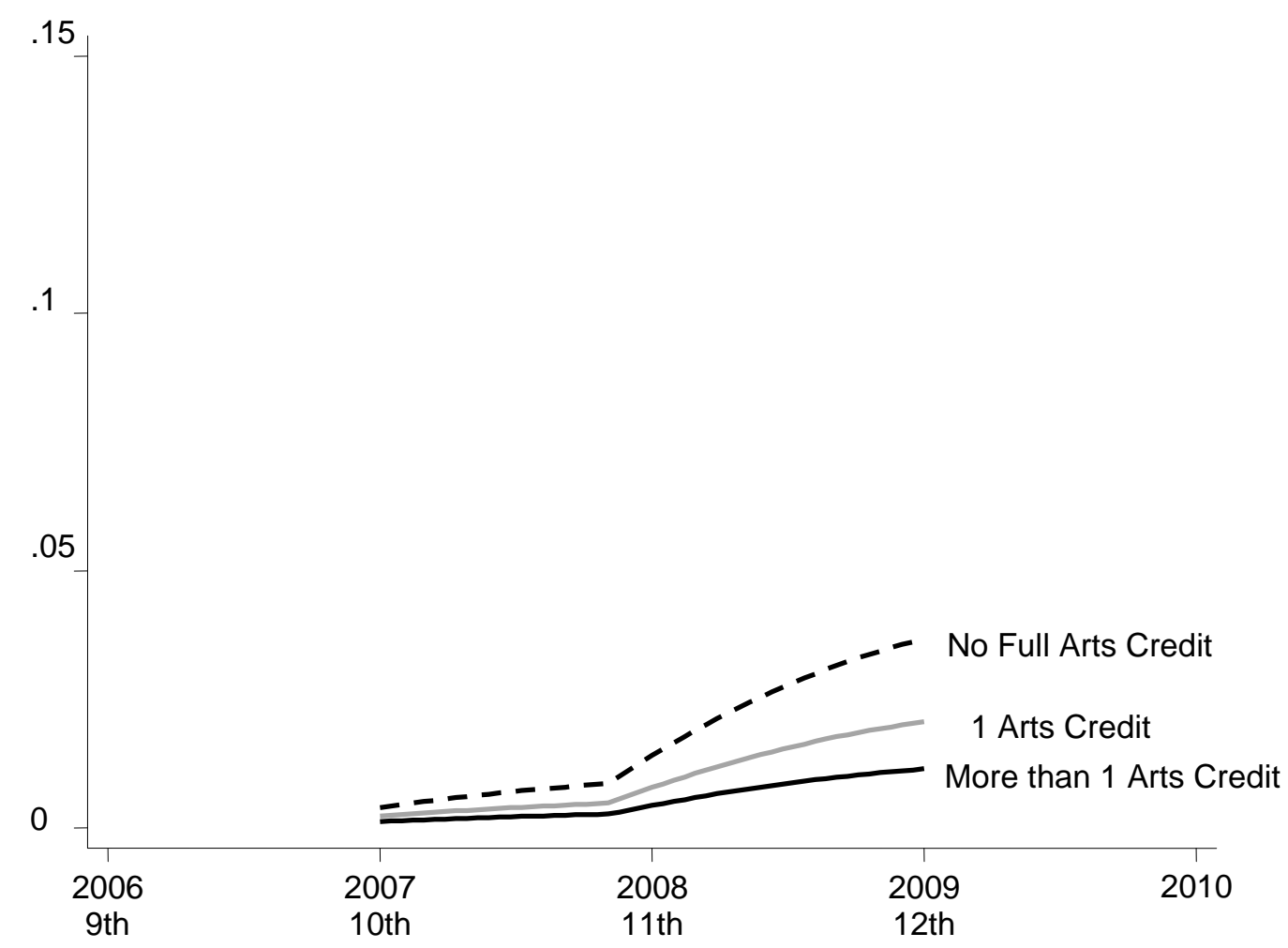

Source: UTD-ERC

Notes: Figure 2 depicts the typical on-time progression to graduation for a baseline student who possesses the average characteristics of the sample. Every year after 2006 includes the students repeating previous grades. We estimate hazards by smoothing the Nelson-Aalen cumulative hazard with a kernel (Gaussian) smoother. Although we follow our cohort for 5 years, beginning and ending years in our time period are not plotted because of the boundary bias kernel smoothing creates due to insufficient data at the endpoints. 